\title{
Sotos Syndrome with Co-Morbid Polycystic Kidney Disease: A Case Report \\ Vered Shkalim-Zemer ${ }^{1,4 *}$, Miriam Davidovits $^{2,4}$, Osnat Konen ${ }^{3,4}$ and Lina Basel-Vanagaite ${ }^{1,5}$
}

${ }^{1}$ Department of Hematology-Oncology, Schneider Children's Medical Center of Israel, Israel

${ }^{2}$ Institute of Pediatric Nephrology, Schneider Children's Medical Center of Israel, Israel

${ }^{3}$ Department of Diagnostic Imaging, Schneider Children's Medical Center of Israel, Israel

${ }^{4}$ Sackler Faculty of Medicine, Tel Aviv University, Tel Aviv, Israel

\begin{abstract}
Sotos syndrome is a genetic condition characterized by excessive growth both prenatally and postnatally, macrocephaly, distinctive facial gestalt, various degrees of learning difficulty and additional clinical features. We report on a 14-month-old male infant with the clinical diagnosis of Sotos syndrome, who was also found to have polycystic kidneys that were first detected by renal sonography at the age of 4 months. This association has been reported only once previously in a patient with Sotos syndrome where autosomal dominant polycystic kidney disease segregated independently in the family. We discuss the possible urogenital findings in Sotos syndrome as well as the association between this syndrome and polycystic kidney disease.
\end{abstract}

Keywords: Sotos syndrome; Renal cysts; Urogenital anomalies

\section{Introduction}

Sotos syndrome is a genetic condition characterized by excessive growth both prenatally and postnatally, macrocephaly, distinctive facial gestalt, various degrees of learning difficulty and additional clinical features $[1,2]$. The findings present in $\geq 15 \%$ of cases include advanced bone age, cranial CT or MRI abnormalities, neonatal hypotonia, poor feeding in infancy, seizures, scoliosis, cardiac anomalies, renal anomalies and other findings [1-3].Various urogenital anomalies have been described in Sotos syndrome [1,4], however, the association of Sotos syndrome and renal cystic disease is not known. We report a case of polycystic kidney disease in a patient with Sotos syndrome.

\section{Patient Report}

A 14-month old boy was referred for evaluation in our genetic clinic due to dysmorphic features and polycystic kidney disease. His non-consanguineous parents are of Jewish-Uzbek origin and this boy is their first and only child. The mother, aged 26 years, is healthy, and the father, aged 33 years, has psoriatic arthritis. During the pregnancy the mother was treated with aspirin. She had a history of three previous spontaneous abortions. From 30 weeks of pregnancy she had premature contractions and was treated with nifedipine. A glucose challenge test was normal, and fetal sonography follow-up was also normal. The boy was born at 32 weeks gestation by vaginal delivery; birth weight was 2360 grams (+2.5SD) and head circumference 31.5 centimeters (85th centile). The Apgar score was 8 at $1 \mathrm{~min}$ and 8 at $5 \mathrm{~min}$. Due to peripheral edema and echymoses observed soon after birth, especially in the upper part of the body, he was hospitalized in the neonatal intensive care unit. His blood pressure at admission was $92 / 53$, heart rate was 112 beats per minute. During the first few days of life he lost $20 \%$ of his weight and developed acute renal failure, with an increase in the creatinine level up to $2.1 \mathrm{mg} / \mathrm{dL}$, urea was $57 \mathrm{mg} / \mathrm{dL}$. He was also found to have hyperkalemia, hyponatremia and microscopic hematuria. He was treated with K-exalate, IV NaCL 0.9\%+ Glucose $5 \%$. and albumin. Normalization of blood electrolytes was achieved and the creatinine level decreased to $0.9 \mathrm{mg} / \mathrm{dL}$. The clinical and laboratory findings were compatible with post-ischemic acute tubular necrosis. Renal sonography showed normal parenchymal structure and echogenicity, and normal flow in the renal blood vessels. Brain sonography showed bilateral subependymal bleeding (grade1). Hearing test, Brain Stem Response Audiomtery (BERA) and echocardiography were normal.

On follow-up he was found to have global developmental delay (motor, speech, communication). He was treated by physiotherapy from the age of 6 months. Evaluation in the neurology clinic revealed increased tonus of all four limbs and axial hypotonicity. Blood count, biochemistry profile, CPK, pyruvate, lactate, ammonia, plasma amino acids and Very Long Chain Fatty Acids (VLCFA) were all normal. Electroencephalogram (EEG) was normal. Brain MRI at the age of 10 months showed hyperintensity of the white matter and extraventricular obstructive hydrocephalus. The corpus callosum was somewhat thin, without evidence of brain dysplasia or heterotopia. $\mathrm{X}$-ray of the lumbar and sacral spine was normal. Serology for TORCH was negative. Ophthalmologic examination including fundoscopy at the age of 10 months was normal. On abdominal sonography at the age of 4 months the length of the right kidney was found to be $5.7 \mathrm{~cm}$., while that of the left kidney was $7 \mathrm{~cm}$. Parenchyma with mild diffuse hyperechogenicity of the cortex was also found. There was a $2 \mathrm{~mm}$ diameter cyst in the right kidney and another same diameter in the left kidney. There were also many other smaller cysts in both kidneys, and the collecting system and urinary bladder were normal. The rest of the abdominal viscera were also normal. Repeated renal sonography at the ages of 7 and 11 months showed the same findings (Figure 1a). Renal sonography of both parents was normal. On follow-up at the age of 20 months, renal function tests and urinalysis were normal.

Evaluation in our genetics clinic at the age of 14 months revealed physical findings and dysmorphic features compatible with the diagnosis of Sotos syndrome (Figure $1 \mathrm{~b}$ ): the head circumference was $50.3 \mathrm{~cm}$. (2 SD above the mean). The mother's head circumference was $55.7 \mathrm{~cm}$. (60th centile) and the father's was $55.5 \mathrm{~cm}$. (40th centile). The child's height was $83 \mathrm{~cm}$. (90th centile) and weight $12.5 \mathrm{~kg}$ (95th centile). The head was dolichocephalic with a broad forehead; he had down-slanting palpebral fissures, hypertelorism, a high arched palate and pointed mandible. The hands and feet were large. Areas of

*Corresponding author: Vered Shkalim-Zemer, Department of HematologyOncology, Schneider Children's Medical Center of Israel, Israel, Tel: +972-3-9253762; E-mail: shine6@walla.co.il

Received September 03, 2015; Accepted October 13, 2015; Published October 20,2015

Citation: Shkalim-Zemer V, Davidovits M,Konen O, Basel-Vanagaite L (2015) Sotos Syndrome with Co-Morbid Polycystic Kidney Disease: A Case Report. J Clin Case Rep 5: 612. doi:10.4172/2165-7920.1000612

Copyright: () 2015 Shkalim-Zemer V, et al. This is an open-access article distributed under the terms of the Creative Commons Attribution License, which permits unrestricted use, distribution, and reproduction in any medium, provided the original author and source are credited. 
hypopigmentation were observed over the central area of the chest, in the left antecubital area expanding to the flexor region of the left arm, and on the left buttock. The distribution was patchy with irregular margins. We re-examined him at the age of 20 months and the findings were as follows: head circumference was $52 \mathrm{~cm}$ (2 SD above the mean), height $93.5 \mathrm{~cm}$ (95th centile), and weight $15.2 \mathrm{Kg}$ (98th centile). His hand lengths were: right $12.1 \mathrm{~cm}(+3 \mathrm{SD})$ and left $12.3 \mathrm{~cm}(+3 \mathrm{SD})$, and foot lengths were: right $15.8 \mathrm{~cm}(+3 \mathrm{SD})$ and left $16.3 \mathrm{~cm}(+3 \mathrm{SD})$. An $\mathrm{X}$-ray of the left hand showed normal structure and shape of bones and the bone age was compatible with 2 years. The family refused molecular analysis both for Sotos syndrome (NSD1) and autosomal dominant Polycystic Kidney Disease (PKD1 and PKD2).

\section{Discussion}

Urogenital abnormalities were present in seven out of eight $(88 \%)$ of a group of Japanese patients with Sotos syndrome [5]. In the American and European literature, urogenital anomalies have also been reported, although the incidence was lower. Cases of urogenital disorders accompanying Sotos syndrome are summarized in Table $1[1,4]$. There is a well known association between renal cysts and certain genetic syndromes such as tuberous sclerosis, Von HippelLindau syndrome, medullary sponge kidney and orofaciodigital syndrome type $1[6,7]$. Cefel et al. [8] reported a case of Sotos syndrome presenting with chronic renal failure due to autosomal dominant polycystic kidney disease (ADPKD) in a 22-year-old male patient [8]. Ultrasonographic examination of the patient, his father, brother and sister revealed polycystic kidneys, indicating that polycystic kidney disease segregated as an independent trait in this family. However, renal failure was present only in the patient with Sotos syndrome, who also had considerably larger cysts $(7-8 \mathrm{~cm})$ than other family members $(<1 \mathrm{~cm})$. The authors suggested that the underlying mechanism responsible for the somatic overgrowth in Sotos syndrome may also be linked with the development of larger cysts and earlier onset of renal failure in ADPKD [8].

Our patient presented with polycystic kidney disease, which was

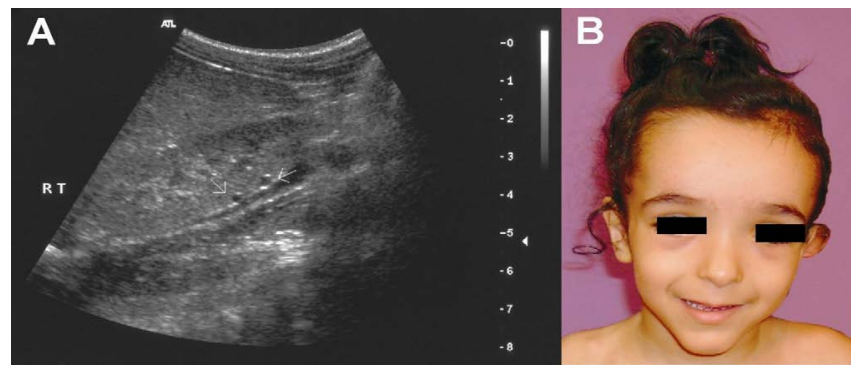

Figure 1: A- Sonography of right kidney performed at the age of 11 months demonstrating multiple tiny cysts, two of which are shown in the image (arrows); B- the child's face.

\begin{tabular}{|l|l|}
\hline Renal & $\begin{array}{l}\text { Hydronephrosis } \\
\text { Hypoplastic kidneys } \\
\text { Renal agenesis } \\
\text { Double collecting system Chronic renal failure Polycystic kidney }\end{array}$ \\
\hline $\begin{array}{l}\text { Bladder/ureter/ } \\
\text { urethra }\end{array}$ & $\begin{array}{l}\text { Vesicourethral reflux } \\
\text { Bladder diverticulae/nodule } \\
\text { Hypospadias }\end{array}$ \\
\hline Testis & $\begin{array}{l}\text { Cryptorchidism } \\
\text { Testis redux }\end{array}$ \\
\hline
\end{tabular}

Table 1: Urogenital anomalies reported in association with Sotos syndrome (adapted from Baujat and Cormier- Daire, 2007, and Visser and Matsumoto, 2003). first diagnosed at the age of 4 months. Renal US in both the parents was normal. It is most likely that the polycystic kidneys found in our patient are part of his Sotos syndrome. However, the possibility of incomplete penetrance due to young parental age or autosomal dominant polycystic kidney disease with a de novo mutation cannot be excluded. In affected individuals with autosomal dominant polycystic kidney disease renal cysts present with increasing frequency with age. More than $90 \%$ of affected individuals will demonstrate cystic abnormalities by 20 years of age. Some patients have early onset of the disease (in utero or in the first year of life). The reason for early onset is not known [9]. De novo mutations occur in about $10 \%$ of affected individuals with autosomal dominant polycystic kidney disease [7]. It should be emphasized that although the diagnosis of Sotos syndrome is mainly based on clinical signs (accelerated growth, acromegalic appearance, mental retardation and various organ abnormalities), the diagnosis of sporadic APDKD in a child would be more complex. It is difficult to identify a polycystic kidney in absence of a positive family history and without performing the genetic analysis. It is also reasonable to think that the acute tubular necrosis, occurred at birth, would have caused the damage to the tubular epitelium and facilitated the cysts formation. Therefore, a longer follow up or the genetic tests are required to confirm the APDKD diagnosis [10].

\section{Conclusions}

This is the first report of polycystic kidney disease in a patient with Sotos syndrome and no family history of autosomal dominant polycystic kidney disease. We suggest that every patient with Sotos syndrome should undergo repeated sonographic evaluation in order to exclude progressive renal cystic disease.

\section{References}

1. Baujat G, Cormier-Daire V (2007) Sotos syndrome. Orphanet J Rare Dis 2: 36.

2. Ko JM (2013) Genetic syndromes associated with overgrowth in childhood Ann Pediatr Endocrinol Metab 18: 101-105.

3. Tatton-Brown K, Rahman N (2007) Sotos syndrome. Eur J Hum Genet 15 264-271.

4. Visser R, Matsumoto N (2003) Genetics of Sotos syndrome. Curr Opin Pediatr 15: 598-606.

5. Moriyama M, Terashima K, Fukushima Y, Kuroki Y (1984) [Urogenital anomalies in patients with Sotos syndrome]. Nihon Hinyokika Gakkai Zasshi 75: 591-593.

6. Pei $Y(2006)$ Diagnostic approach in autosomal dominant polycystic kidney disease. Clin J Am Soc Nephrol 1: 1108-1114.

7. www.geneclinics.org

8. Cefle K, Yildiz A, Palanduz S (2002) Chronic renal failure in a patient with Sotos syndrome due to autosomal dominant polycystic kidney disease. Int $\mathrm{J}$ Clin Pract 56: 316-318.

9. Rizk D, Chapman AB (2003) Cystic and inherited kidney diseases. Am J Kidney Dis 42: 1305-1317.

10. Neumann HP, Bacher J, Nabulsi Z, Ortiz Brüchle N, Hoffmann MM, et al. (2012) Adult patients with sporadic polycystic kidney disease: the importance of screening for mutations in the PKD1 and PKD2 genes. Int Urol Nephrol 44 1753-1762. 